\title{
MIS in the MBA is broken! Do we want to fix it or ditch it?
}

\author{
E. Jordan \\ Macquarie Graduate School of Management \\ Macquarie University, NSW 2109, Australia \\ Phone: +61298509041 Fax: +61298509019 \\ Email: Ernest.Jordan@mq.edu.au
}

\begin{abstract}
This paper assesses the current standard MIS class that is part of a standard MBA. The needs for information technology education has been changing rapidly but the textbooks that are used have only been evolving slowly. Has a mismatch been reached? What should be done now? This paper argues that there are two revolutionary, rather than evolutionary, alternatives.
\end{abstract}

\section{Keywords}

Management information systems, MBA programme, end user systems management

\section{INTRODUCTION}

For many individuals, businesses and universities, the paramount management education achievement is the Masters in Business Administration, the MBA. For business schools this course is the 'premium product' that establishes the name and prestige of the institution. While there are alternative models, such as the integrated MBA at the University of Denver (Slater, McCubbrey and Scudder, 1995), in most MBAs students are required to study a range of compulsory, discipline-based subjects, together with a number of elective subjects. It is a commonplace that the compulsory subjects include one that emphasises information systems and their management. This subject is commonly referred to as 'management information systems' or 'management of information systems' but will be referred to here simply as 'MIS'.

The term 'MIS' was developed in the era of centralised, mainframe-based computing 
when in reality data processing was the norm and management information was the pious hope. Here we challenge the place of MIS in the MBA curriculum by particularly referring to the leading-edge practices of management in a large, technology-aware organisation.

In many universities the MIS class is taught as a formal class subject, using a text book approach, accompanied by the use of case studies. A large number of text books are available on the market, with many of them now into higher editions. The texts are mostly US in origin and are supported by supplementary teaching material. As IT has changed over time, these texts have been modified to accommodate those changes.

This paper examines the approach taken by textbooks and contrasts it with the current needs of management students. Students may be from the IT function within an organisation, in which case the MIS class is too low in its level and lacking in focus. Other students, from areas outside the IT function of large corporations, will find the standard course and its standard approach delivers them few skills and abilities that they can apply in their work situations. We argue that an approach based upon end user management skill building is most valuable to the majority of students.

\section{WHAT IS WRONG WITH THE MIS CLASS?}

In this section we briefly examine the way in which the teaching of MIS has evolved, particularly in terms of the content of textbooks, and then address our perceptions of limitations: the topics studied, the reliance on case studies, and the failure to design the assessment as carefully as the curriculum.

\subsection{The evolution of teaching of MIS}

One of the first, if not the first, textbook in the area of MIS was the significant work of Gordon Davis (1974). This predated the appearance of MIS Quarterly (1978) and the Journal of Management Information Systems (1985), and represented a success in putting computer systems and their management into a solid academic framework. By the early '80s the first editions of McLeod (1993), Lucas (1994) and Senn (1990) had all appeared; all being texts that were student-oriented, placing less emphasis on theory than in the case of Davis. These texts were designed for MBA classes but reflected the issues of the day: mainframe systems, systems development, and business applications.

Such standard texts have evolved over many editions to maintain contact with the changing technological and business environment. Thus there is now consideration of executive information systems, strategic applications of IT and fourth generation languages, as well as the organisational issues of end user computing, interorganisational systems, and organisational transformation through IT.

Although there has been some evolution in the course content of the compulsory information systems class, the name is usually MIS and it retains a focus on the centralised computing function and the problems faced by the manager of that functional unit of the organisation. Many admirable textbooks exist, such as Lucas (1994), Laudon and Laudon (1995), which have a broad compass, as well as providing depth in some areas. The content of the MIS course will still include introductions to computer 
hardware, software, and networks, the analysis and design of information systems, management of the information systems functional area and selected additional topics.

In some MBAs students will be expected to be computer literate before commencing, in others there will be a literacy class before this MIS class. This area is not included in the issues of this paper, as a level of computer literacy is generally regarded as mandatory for all business studies students. However, it is not unusual to find elementary literacy material included in MIS texts.

\subsection{Limitations in the standard MIS class}

\section{Topics of study}

An MBA is a management qualification, so the topics of study should be the essential knowledge that all managers must have in their grasp. The popularity of the MBA title has led some business schools to offer this course to students with little or no actual experience of business or management. In such cases, it is tempting to teach material that is within the capability of such students to learn. This is a very dangerous step. The reference for the material that is taught must remain with current practice in a business or management environment. A second point concerning the topics studied, is that they must concern areas in which the manager is expected to have to act - where they will be expected to have to make decisions in their workplace. The third guiding principle is that the material should always be 'education' rather than 'training', so that the manager has a foundation to build upon, as the currency of the material fades in the years after graduation.

Using these to guide material selection, we can see that expert systems, artificial intelligence, systems development methodologies, and many more topics cannot be presented in a way that the graduate is able to make decisions about them. These subjects in general are relevant only to students making information systems their area of interest. Every manager needs to know how to deal with a centralised IT function, how to make those difficult make/buy decisions, how and when to outsource, and how to scan for threats and opportunities. Rather than being able to give one line definitions of new technologies, they should be given skills in evaluating the risks inherent in emergent technologies, and techniques to adapt descriptions of technology into business frameworks. These skills are all in the area of end-user computing management.

\section{Case studies}

An important teaching technique in this course, as in most MBA courses, is the case study. Typically students will receive lectures or be expected to read the text material, however much of the learning takes place in the case study analysis sessions. Here students will be expected to apply the knowledge gained to a realistic business situation, carrying out analytic evaluation of a setting, and determining priorities, issues and, occasionally, making judgements. One danger is that the student's knowledge is so superficial that they are unable to benefit from any realistic cases.

Prepared case studies that are included with course material are usually American in origin, and deal with large organisations. For the majority of students in Australia these case studies can only be regarded as 'extreme cases', not typical ones from which they can absorb lessons that can be applied to their own situations. 
There is also the difficulty that for many students, especially the weaker ones, the difficulties faced in the case study are seen only with hindsight, and are thus 'not difficult' or 'non-problems'. The solution is, to them, obvious and the case is simply something to be memorised for the examination. The brilliance, inventiveness or courage displayed by an organisation in a case study is frequently glossed over or underestimated. Those without courage or inventiveness find it difficult to recognise in others.

An ancillary problem associated with the use of case studies is that classroom discussion may appear to be rich and interesting, but only a few people are fully involved. In most cases the majority of the class will be passengers, and so will have had a much reduced learning experience.

\section{Assessment}

Far too little attention is given in discussions of curricula to the important matter of assessment (see for example Silver, Markus and Beath, 1995; Slater, McCubbrey and Scudder, 1995). It is a commonplace that the learning experience of many students will be guided simply by the forms and formats of the assessment. Grand plans envisaged in the careful design of a curriculum can be completely wasted if assessment is mainly multiple-choice tests. I would strongly argue that there is only a very limited place in an MBA course assessment for multiple choice tests. Although it is possible to create such tests that assess effectively over the range of cognitive skills, it is seldom the case. Many test questions rely on memory, others on particular definitions introduced in the text, still others on very limited applications of knowledge. Higher cognitive tasks, such as reflection and evaluation, are not easily introduced into multiple choice tests.

The appropriate design of assessment is one based upon the teaching and learning objectives of the course. If the student is expected to achieve skill $\mathrm{X}$ then there should be some element of the assessment that attempts to determine whether the student has indeed achieved it. Furthermore, every element of the assessment should be capable of being assigned to one of the teaching or learning objectives. An impartial mapping of the assessment activities against the course objectives would, in many cases, find that the assessment concentrates too heavily on too few objectives, assesses knowledge and skills outside the targeted area, and fails completely to assess other objectives.

\section{WHAT IS LEADING EDGE IN MANAGEMENT USE OF IT?}

Today the use of IT has been decentralised and distributed, so that all functional areas of the business have appropriate applications. An alternative model for the knowledge that is needed by the MBA graduate is that of the end-user, and most MIS textbooks give some attention to this approach. However, end-user computing means different things to different people, so we shall look in depth at what is taking place among the trend setters in the world of business to guide us to the required knowledge and skills.

\subsection{Current practice in an IT-aware organisation}

A study into the relationship between the organisational structure of a business and its IT strategy looked at independent business units of a major international bank, called here "Globalbank". The research framework used in the study was the organisational structure 
model of Mintzberg (1979), and in this paper we are particularly concerned with the structural form called the adhocracy.

The adhocracy exists in a complex and dynamic environment, where highly trained people work together using cooperative methods such as liaison devices and organic interaction. The adhocracy is coordinated through mutual adjustment, where the characteristic is of a strong support staff working to collaborate. There is much horizontal specialisation among the team members, many liaison devices throughout the organisation, and selective decentralisation. There are two distinct forms of adhocracy, determined by the target for its output; the operating adhocracy has external customers and the administrative adhocracy supports the rest of its own organisation.

\section{Findings}

Globalbank has pursued a policy of aggressively using IT as a strategic weapon with the aim of becoming more successful in an increasingly competitive marketplace. Furthermore, the practice of decentralisation of business units has enabled those units to pursue strategies that are almost independent, to such an extent that the business units can be regarded as distinct entities with a small set of organisational constraints. Thus the internal business units of Globalbank serve as separate implementations of IT strategy, as a large sample rather than just a single case. In addition, through its innovation and aggressive searching for IT opportunities, Globalbank can serve as a model for other organisations. That is, if any organisation can be successful in the application of IT, Globalbank has both had the opportunity and taken it.

All the development has taken place in an organisational atmosphere of pursuit of excellence through IT. Managers have been IT aware for a long time, and Globalbank has the courage and ability to implement innovative and complex systems. With a (more or less) uniform organisational cultural background and consistent constraints being applied by the management and support groups, the major differences between systems will then be attributable to the business needs and functioning of the units. It makes it possible to investigate the impact of organisational structure without the confounding variables that naturally occur when looking at different companies.

A total of twenty-six business units were studied (Jordan, 1994; Jordan and Tricker, 1995). Eight were found to be what Mintzberg terms 'machine bureaucracies' where IT is used to reduce costs, standardise processing and permit strong management control. Others were found to be simple structures and professional bureaucracies, however, of principal concern here are the ten units classified as adhocracies:

$\begin{array}{ll}\text { World Customer Group, WCG, } & \text { Corporate Banking Unit, CBU, } \\ \text { China Customer Unit, CCU } & \text { Institutional Investment Management, IIM, } \\ \text { Structured Finance Unit, SFU, } & \text { Price Risk Management, PRM, } \\ \text { Project Finance Unit, PFU, } & \text { Industry Risk Management, IRM, } \\ \text { Treasury Marketing, TM, } & \text { Corporate Finance Unit, CFU. }\end{array}$

By way of explanation, most of these business unit names are industry standard, however WCG is a specialised unit that serves only major multinational customers, and TM sells foreign exchange, interest rate and other instruments to corporate clients.

PRM and IRM are administrative adhocracies, concerned with problems inside Globalbank, and the remainder are operating adhocracies that deal with customers' problems. In all units professional staff use their skills more on unique cases or projects than on routine action, although there is some routine in all of their work. There is much 
dealing with other professional or expert staff in different domains of expertise. Creativity, originality and the ability to coordinate with other disciplines are key attributes for staff in these areas. In all areas standard professional skills (in project finance, price risk assessment, etc.) are used but a variation is found in WCG where Globalbank has created its own profession of the WCG specialist. They are only interchangeable with WCG specialists from other countries.

CBU and CCU are concerned with setting up new business areas, while TM even has a transaction processing function in the unit. All units are concerned with the design and/or the marketing of products. CBU creates management information for its own use. There is little use of IT to directly support staff activities beyond the use of PCs to model alternative proposals. The electronic mail network is used in all units to work with people in other locations, and, in the case of PRM, to collect information. Email is critical to the success of WCG, SFU, PRM, PFU and CCU. The existence of a telecommunications network permits the processing that WCG and CCU market.

Specific software that enhances the functioning of the staff in used in SFU, PRM, IIM and TM, with the most sophisticated software used by any of the groups being in SFU and PRM. General purpose software, such as PC packages (especially spreadsheets), is used for enhanced performance of PFU, CFU and WCG. Because CFU's business networks extend outside Globalbank, a mobile telephone is used, one of the few directly used by any business unit.

\subsection{An emergent organisational form}

This study revealed an emergence of business units organised as adhocracies (Mintzberg, 1979) that were using IT to support their organic, flexible project-based organisation. Precisely as indicated by Mintzberg, there were no controlling, centralised information systems that aimed at conformity. In each group technology was applied that supported the particular form of tasks that the group was undertaking, but because the tasks were usually one-off projects, the most appropriate technology was both flexible and adjusted to cope with the particular task at hand.

Communication technologies, especially email, and flexible modelling tools, such as spreadsheets, were the forms of technology that dominated. However, an important issue is that all of the professional staff, who were employed in these adhocracies, were computer literate and sufficiently informed that they could decide upon the IT that met their needs. On occasions they may have needed to draw upon the IT staff for support, but most of the time they were able to develop their own spreadsheet and data base models, and communicate these not only to other professionals around the organisation, but also to their support and administrative staff.

At the time of the study there were few group support tools available, such as Lotus Notes, GrapeVINE, or Group Systems, however an intelligent user of electronic mail can perform many of the tasks for which the more specific group support tools are designed.

An additional remark should be made to justify that this form is 'emerging'. Most of these adhocracies had developed from an organisational form that Mintzberg terms the professional bureaucracy. In this form the professional person is engaged solely in 'routine' work that is standard for the profession in which they are trained. They have a more 'blinkered' view, and deal with a restricted range of problems. We are perhaps more familiar with this in the medical setting where each specialist deals only with 
problems in their domain. The use of a multi-profession task force to deal with a specific problem is a relatively rare event. What has happened at Globalbank is that the task force has become more and more common, with the routine work being delegated to paraprofessionals or to computer systems. As the proportion of multi-profession team work increases, the unit becomes an adhocracy rather than a professional bureaucracy.

\section{WHAT SHOULD THE MBA STUDENT LEARN ABOUT IT?}

Fix it or ditch it? MIS as a separate subject could be abandoned if the appropriate level of use and application of IT were included in other subjects. Eventually this should happen, as IT becomes a pervasive technology that cannot be isolated from its context. In many ways this has already been achieved by the integrated MBA at the University of Denver (Slater, McCubbrey and Scudder, 1995) where there is no individual IT subject.

Until that day (and accepting the territorial and political aspects of curriculum design) the majority of MBA course will include an MIS subject, so we need to fix it. It needs to address two distinct areas: the student's own performance as a manager, and the contribution of their managed domain to the organisation's performance. An outline of the course that would fit both the adhocratic professional and end user manager follows.

\section{Aim}

On completion of this course the student should be able to use IT to enhance their management effectiveness and productivity, and the performance of the organisation.

\section{Specific objectives include:}

be able to incorporate IT into their own work practices,

be able to adapt to changes in technology,

be able to assess the organisational impact of a new technology,

be able to assess the risks inherent in a specific project,

be able to evaluate alternative IT proposals.

\section{Content}

Centralised and decentralised information resources. End-user computing, data models, practical personal productivity skills, data bases for executive information systems and management support systems, spreadsheets as decision support systems and expert systems. Technology surveys, risk assessments, organisational and individual impacts of technology. Ethical issues.

\section{Teaching strategies}

Formal lecture material is only necessary so that the students can build a framework upon which to accumulate knowledge, skills and practice. Much of the learning needs to be student initiated, except in the case where students have little or no real world business experience, or little drive to facilitate their own education.

All students will have either current or recent experience of IT. This needs to be the basis upon which the teaching is based. Students can write case analyses of particular 
situations with which they are familiar and the instructor can introduce new technologies for the students to assess.

\section{REFERENCES}

Davis, G.B. (1974) Management information systems: conceptual foundations, structure and development. McGraw-Hill, New York.

Jordan, E. (1994) Information strategy and organisation structure. Information Systems Journal, 4, 4, 253-270.

Jordan, E. and Tricker, R.I. (1995) Information strategy: alignment with organisation Structure. Journal of Strategic Information Systems, 4, 4.

Laudon, K.C. and Laudon, J.P. (1995) Essentials of management information systems: organisation and technology. Prentice-Hall Inc., Englewood Cliffs, NJ.

Lucas, H.C. Jr (1994) Information systems concepts for management, 5th ed. McGrawHill, San Francisco.

McLeod, R. Jr (1993) Management information systems: a study of computer-based information systems, 5th ed. Macmillan, New York.

Mintzberg, H. (1979) The structuring of organisations. Prentice-Hall, Englewood Cliffs, NJ.

Parker, C. (1989) Management information systems: strategy and action, McGraw-Hill International, Singapore.

Senn, J.A. (1990) Information systems in management, 4th ed. Wadsworth Inc., Belmont, CA.

Silver, M.S., Markus, M.L. and Beath, C.M. (1995) The information technology interaction model: a foundation for the MIS core course. MIS Quarterly, 19, 3, 361390.

Slater, J.S., McCubbrey, D.J. and Scudder, R.A. (1995) Inside an integrated MBA: an information systems view. MIS Quarterly, 19, 3, 391-410.

\section{BIOGRAPHY}

Dr Jordan is currently an Associate Professor in Management at the Macquarie Graduate School of Management in Sydney. Dr Jordan had some ten years experience in the development of information systems in commerce and industry before entering the academic world. He has just returned to Australia after eight years at City University of Hong Kong, where he helped in the establishment of an information systems department and its bachelor's and master's degree programmes. His research interests include the strategic aspects of IT, executive information systems, and enhancing teamwork in information systems development. He has published in the International Journal of Information Management, Information Systems Journal, Journal of Strategic Information Systems, and the Australian Computer Journal. 